\title{
Pilot-Scale Production of Cellulosic Nanowhiskers With Similar Morphology to Cellulose Nanocrystals
}

\author{
Huihui Wang ${ }^{1,2}$, Jonathan J. Zhu ${ }^{3}$, Qianli Ma4, Umesh P. Agarwal' ${ }^{2}$, Roland Gleisner', \\ Richard Reiner', Carlos Baez ${ }^{2}$ and J. Y. Zhu'2* \\ ' State Key Laboratory of Pulp and Paper Engineering, South China University of Technology, Guangzhou, China, ${ }^{2}$ USDA \\ Forest Service, Forest Products Laboratory, Madison, WI, United States, ${ }^{3}$ Department of Biochemistry, University \\ of Wisconsin-Madison, Madison, WI, United States, ${ }^{4}$ International Center for Bamboo and Rattan, Beijing, China
}

OPEN ACCESS

Edited by:

Muhammad Wajid Ullah

Huazhong University of Science and Technology, China

Reviewed by: Rajendra Kumar Singh, Institute of Tissue Regeneration Engineering (ITREN), South Korea

PaYaM ZarrinTaj,

Oklahoma State University,

United States

*Correspondence:

J. Y. Zhu

junyong.zhu@usda.gov

Specialty section: This article was submitted to Biomaterials,

a section of the journal Frontiers in Bioengineering and

Biotechnology

Received: 23 May 2020

Accepted: 20 August 2020 Published: 04 September 2020

Citation:

Wang $H$, Zhu JJ, Ma Q, Agarwal UP, Gleisner R, Reiner R, Baez C and Zhu JY (2020) Pilot-Scale

Production of Cellulosic

Nanowhiskers With Similar

Morphology to Cellulose

Nanocrystals.

Front. Bioeng. Biotechnol. 8:565084. doi: 10.3389/fbioe.2020.565084
This study describes a class of cellulosic nanomaterials, cellulosic nanowhiskers (CNWs), and demonstrates scaled-up production with acid recovery using less expensive equipment made of common stainless steel rather than glass-lined steel. CNWs produced using concentrated maleic acid (MA) hydrolysis followed by mechanical fibrillation have morphology similar to MA-produced cellulose nanocrystals (CNCs) and sulfuric-acid-produced CNCs (S-CNCs) but differ in crystallinity. Applications of CNWs as a substitute for CNCs for which morphology and surface charge, rather than crystallinity, are the pertinent characteristics are presented. The tested CNW suspensions have a wider viscosity range of 0.001 to 1000 Pa.s over a variety of shear rates of 0.01 to $1000 \mathrm{1} / \mathrm{s}$ compared to S-CNCs of 0.001 to $0.1 \mathrm{~Pa}$.s and are better suited for applications such as rheology modification and 3D printing. This study proposes CNWs as a less expensive and sustainable replacement for CNCs in applications that do not require crystalline properties.

Keywords: cellulose nanocrystals (CNCs), cellulose nanowhiskers (CNWs), cellulose nanofibrils (CNFs), mechanical fibrillation, suspension rheology, carboxylation, dispersion, acid hydrotrope

\section{INTRODUCTION}

Cellulosic nanomaterials (CNMs) have attracted great interest for a variety of applications due to the renewability of cellulosic raw materials and their unique mechanical and optical properties (Mark, 1967; Revol et al., 1992; Šturcová et al., 2005). To the general scientific community, the term CNMs usually refers to two types of materials: (1) cellulose nanocrystals (CNCs), mainly sulfuric acid CNCs (S-CNCs) produced by concentrated sulfuric acid hydrolysis and dialysis for separation; and (2) cellulose nanofibrils (CNFs), produced by mechanical fibrillation with or without chemical/enzymatic pretreatment of cellulosic fibers. CNCs are highly crystalline, as implied by the name, generally with length of $50-500 \mathrm{~nm}$, or degree of polymerization (DP) of 100300 (Battista, 1950; Battista et al., 1956; Nishiyama et al., 2003), and diameter of 3-10 nm. However, the range of crystallinity for a material to be classified as CNCs has not been established in literature.

Difficulties in accurately measuring $\mathrm{CNC}$ crystallinity using traditional $\mathrm{x}$-ray diffraction technique (Segal et al., 1959; Park et al., 2010) have added more ambiguity to the definition 
of CNCs. Further compounding the problem is the fact that existing crystallinity measurement techniques, including $\mathrm{x}$-ray diffraction (Segal et al., 1959), NMR (Larsson et al., 1997) and Raman (Agarwal et al., 2010), are ensemble measurements over a volume of cellulose sample and therefore spatially averaged rather than resolved to the cellulose nanofibrils/nanocrystals level. This has led to erroneous references to morphologically CNC-like cellulosic whiskers without high crystallinity as being CNCs (Montanari et al., 2005; Hirota et al., 2010; Leung et al., 2011; Anderson et al., 2014).

We suggest that differentiating morphological dimensions from crystallinity is highly important. CNCs have been used for many applications where high crystallinity is not important, such as rheology modifiers (Ojala et al., 2016; Grishkewich et al., 2017; Molnes et al., 2018), hydrogels (Hou et al., 2017; Kim et al., 2017; De France et al., 2019) and 3D printing (Jia et al., 2017; Palaganas et al., 2017; Hausmann et al., 2018; Sultan and Mathew, 2018; Wang et al., 2018; Li et al., 2019) for which dispersibility and proper morphology, not crystallinity, are the keys to performance. This has significant commercial implications because the cost of producing CNCs is often higher than for other CNMs. Furthermore, difficulties in economic recovery of mineral acids (mainly sulfuric acid) and the need for salt disposal pose significant challenges. Current utilization of the expensive S-CNCs for applications that do not require crystallinity is primarily due to (1) ready market availability, because several S-CNC pilot facilities and a commercial facility have been established, and (2) lack of recognition of the diversity of CNMs, as reflected by the generalization of CNMs as either CNCs (individually separated crystalline particles) or CNFs.

Here we discuss an "in-between," that is, individually separated, charged, and dispersible CNMs with morphology similar to CNCs but without the specification of crystallinity, which allows flexibility in processing to achieve sustainable and economic production. We call this class of CNMs cellulosic nanowhiskers (CNWs), because the term, though not clearly defined, has been previously used (Braun and Dorgan, 2009; Wang et al., 2012a). Individually separated nanoscale cellulosic whiskers were observed in TEM images of substantially fibrillated cellulose fibers (Wang et al., 2012a). Nanoscale cellulosic whiskers were also obtained from mechanical fibrillation of the cellulosic solid residue (CSR) after concentrated sulfuric acid hydrolysis of bleached fibers (Wang et al., 2012b). They have a similar morphology to CNCs but with low crystallinity due to mechanical fibrillation as measured by x-ray diffraction (Wang et al., 2013). Therefore, they are not CNCs.

Previously, we demonstrated integrated production of both CNCs and CNFs at lab-scale (i.e., gram scale) with desired morphologies using dicarboxylic acids (Chen et al., 2016; Wang et al., 2017). Dicarboxylic acids are weak acids resulting in low CNC yields, but the hydrolyzed CSR can be fibrillated into CNMs for substantially higher overall solids (or CNM) yield. Moreover, as weak solid acids with low solubility dicarboxylic acids have substantial advantages over conventional strong mineral acids in terms of acid recovery (Cai et al., 2020a,b) and lower corrosiveness. Furthermore, maleic acid is a U.S. Food and Drug Administration (FDA)-approved indirect food additive per Code of Federal Regulations 21CFR175-177, and therefore with no environmental impact.

The novelty of the present work is to demonstrate pilotscale production and characterization of alternative CNMs, i.e., CNWs, as a viable substitute for the crystalline but expensive CNCs, with the objective of sustainable processing at higher yields, better use, and broader commercialization of CNMs. Two different acids were chosen to investigate the scalability of each, as well as different starting materials to produce both lignin free CNWs and lignin-containing CNMs (LCNMs).

\section{MATERIALS AND METHODS}

\section{Materials}

Bleached kraft eucalyptus dry lap pulp (BEP) from Fibria (Aracruz, Brazil) was used for producing lignin-free CNMs. As described elsewhere (Chen et al., 2016; Zhou et al., 2019), BEP was first soaked in distilled water for $24 \mathrm{~h}$ and then disintegrated at $10 \%$ solid consistency in a lab disintegrator (TMI, Ronkonkoma, NY, United States) at room temperature for 10,000 revolutions at $312 \mathrm{rpm}$. Disintegrated pulp was collected after vacuum filtration.

Medium density fiberboard (MDF) fibers were used to produce lignin-containing CNMs. MDF fibers were produced by disk-refining birch (B. papyrifera) wood chips in a $30.5-\mathrm{cm}$ pressurized disk refiner (Sprout-Bauer, model 1210P, Muncy, PA, United States), as described previously (Bian et al., 2017b). Birch wood logs were from a tree that was approximately 35 years old harvested from the Rhinelander Experimental Forest, USDA Forest Service Northern Research Station, Rhinelander, WI, United States. After hand debarking and chipping at the USDA Forest Products Laboratory, Madison, WI, United States, wood chips were pre-steamed at $165^{\circ} \mathrm{C}$ for $10 \mathrm{~min}$ with a steam pressure of $0.72 \mathrm{MPa}$ before being fed to the disk refiner at approximately $1 \mathrm{~kg}$ (OD weight)/min. Resulting pulp fibers were stored in a plastic bag in a refrigerator for further processing.

Anhydrous maleic acid (MA) and p-toluenesulfonic acid $(p$-TsOH), both ACS reagent grade, were purchased from Sigma-Aldrich (St. Louis, MO, United States). A commercial endoglucanase, FiberCare ${ }^{\circledR}$, was complimentarily provided by Novozymes North America (Franklinton, NC, United States). Protein content of FiberCare ${ }^{\circledR}$ was assayed at $7.53 \mathrm{mg} / \mathrm{mL}$.

\section{Scaled-Up Production of CNMs}

Preliminary small-scale fractionations using $10 \mathrm{~g} \mathrm{MDF}$ and $p$-TsOH were conducted under a wide range of conditions to obtain predictive delignification information for process scaleup. In the present study, $750 \mathrm{~g}$ batches of BEP and MDF fibers were hydrolyzed using concentrated aqueous $\mathrm{MA}$ and $p-\mathrm{TsOH}$, respectively, following a scheme depicted in Figure 1. MA was applied to BEP fibers and the stronger acid $p$-TsOH was chosen for the MDF fibers. The different hydrolysis conditions were represented by MxxTyytzz for BEP and $\mathrm{P} x x \mathrm{~T} y y t z z$ for MDF, where $\mathrm{M} x x$ or $\mathrm{P} x x$ denote $\mathrm{MA}$ or $p$-TsOH acid concentration in $x x$ wt $\%$, Tyy and $\mathrm{t} z z$ denote hydrolysis temperature in $y y$ degree Celsius and reaction duration in $z z$ min. All hydrolysis reactions were carried out in a $21-\mathrm{L}$ rotating wood pulping 


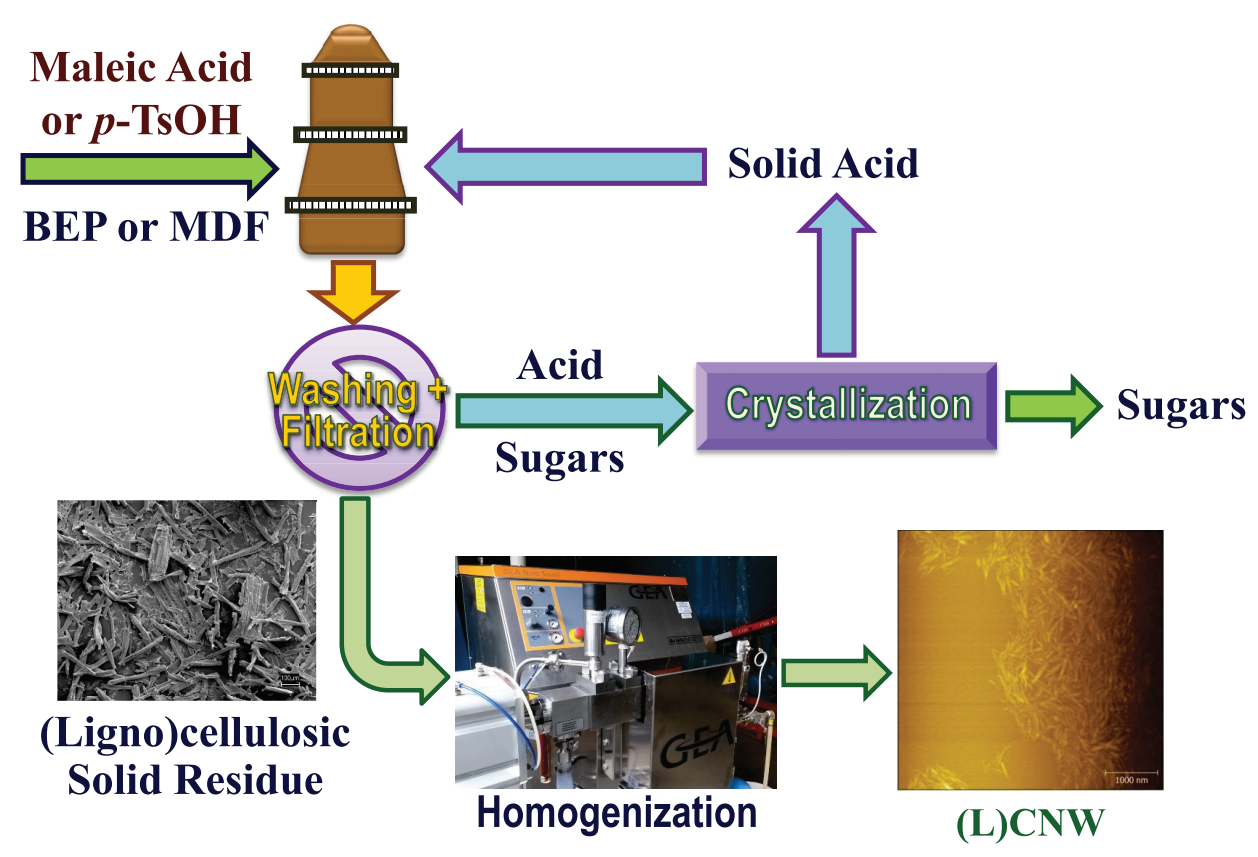

FIGURE 1 | Schematic process flow diagram for pilot-scale production of (ligno)cellulosic nanowhiskers (L)CNWs without separating CNCs (integrated process).

digester at a solid-to-liquor mass ratio of 1:10. Heat-up to the target hydrolysis temperature was only a few minutes. At the end of the reaction period, solids were separated by screen filtration, thoroughly washed, and then fed into a pilot-scale homogenizer (GEA Noro Soavi Ariete NS3015, GEA) for nanoscale fibrillation. The number of passes was varied so as to vary the degree of fibrillation.

\section{Analytical Methods}

Chemical composition of untreated and pretreated BEP fibers was analyzed as described previously (Luo et al., 2010) using the standard two-step acid hydrolysis procedure, with resultant hydrolyzates analyzed by ion chromatography using pulsed amperometric detection (ICS-5000, Dionex, Sunnyvale, CA, United States).

\section{Characterizations of CNMs}

Crystallinity: For cellulose crystallinity estimation by Raman spectroscopy, the 380-Raman method (Agarwal et al., 2010, 2013) was used. The method determines the crystallinity of a cellulosic sample based on the ratio of Raman scattering intensity at $380 \mathrm{~cm}^{-1}$ over the intensity at $1096 \mathrm{~cm}^{-1}$ through calibration using the crystallinity data from wide angle $\mathrm{x}$-ray scattering (WAXS) measurements of a set of well-defined cellulosic samples. CNM samples were analyzed in triplicate using a Bruker MultiRam spectrometer (Bruker Instruments Inc., Billerica, MA, United States) equipped with a 1064-nm 1000-mW continuous wave (CW) diode-pumped Nd:YAG laser operated at $600 \mathrm{~mW}$ for sample excitation. Sample pellets were made from $\sim 0.1 \mathrm{~g}$, and 2048 scans were co-added. Bruker OPUS 7.2 software was used to determine peak positions and process the spectral data.
Some samples produced too much fluorescence, so their 380Raman crystallinity could not be determined. Wide-angle X-ray diffraction measurements of crystallinity were carried out using a Bruker D8 Discover system with $\mathrm{Cu}-\mathrm{K} \alpha$ radiation (Bruker Corp., Billerica, MA, United States) at the Material Science Center, University of Wisconsin (Madison, WI, United States). As described previously (Chen et al., 2015), CNM suspensions were first freeze-dried to avoid film formation and to minimize the potential for preferred orientation in the samples. The freezedried samples were pressed into 100-mg, 8-mm-diameter pellets using hydraulic compression (180 MPa). A spot size of $0.5 \mathrm{~mm}$ was used. Scattering signals were collected in a 2 -min period for every specimen. CrI was calculated according to the Segal method (Segal et al., 1959): $C r I=100 \times\left(I_{200}-I_{\mathrm{am}}\right) / I_{200}$ with $I_{\mathrm{am}}$ the intensity at $2 \theta=18^{\circ}$.

\section{Atomic Force Microscopy (AFM)}

The morphology of CNM samples was characterized by AFM (AFM Workshop, Signal Hill, CA, United States) using a tip curvature radius and vibration frequency of 10-15 nm and 160$225 \mathrm{kHz}$, respectively. Approximately $0.1 \mathrm{wt} \%$ suspensions were dispersed with sonication, then a drop of each suspension was placed onto a clean mica surface and air-dried overnight at room temperature prior to characterization.

\section{Thermogravimetric Analyses (TGA)}

The thermal stability of CNM samples was analyzed using a Pyris 1 TGA (Perkin-Elmer, Inc., Waltham, MA, United States). Samples were dried overnight at $105^{\circ} \mathrm{C}$. Aliquots of approximately 8-10 $\mathrm{mg}$ were heated from ambient temperature to $700^{\circ} \mathrm{C}$ at a rate of $20^{\circ} \mathrm{C} / \mathrm{min}$, with a highly purified nitrogen 
stream at $20 \mathrm{~mL} / \mathrm{min}$ continuously passing into the furnace during pyrolysis.

\section{Surface Properties}

The carboxyl group content of CNM samples was determined by the back-titration method (Jeon et al., 1999; Stojanović et al., 2005). Briefly, $50 \mathrm{mg}$ of CNF suspension (0.2 wt $\%$ ) was carefully added to $10 \mathrm{~mL}$ of $0.1 \mathrm{M} \mathrm{NaOH}$ maintained at $50^{\circ} \mathrm{C}$ and stirred for $30 \mathrm{~min}$. The excess $\mathrm{NaOH}$ was back-titrated with standard $0.025 \mathrm{M} \mathrm{HCl}$ using phenolphthalein as the indicator. Surface charge was measured using a zeta potential analyzer (Nanobrook Omni, Brookhaven Instruments, Holtsville, NY, United States) based on monitoring electrophoretic mobility using phase analysis light scattering (PALS). The same instrument was used for DLS particle sizing. Each sample was circulated five times for a total of $10 \mathrm{~min}$ to obtain averaged size. These two methods were developed for spherical particles but were used as an approximation for CNWs in this study.

\section{Suspension Rheology}

Rheological analyses of CNC, CNW, and CNF suspensions were performed using a rotational rheometer (MCR 302 Anton Paar Physica) with 43-mm-diameter steel plates in parallel plate geometry. Steady-state shear viscosity curves were generated for all samples in a shear rate range of 0.01 to $1000 \mathrm{~s}^{-1}$. The time required to reach steady state at $0.01 \mathrm{~s}^{-1}$ was determined by a transient test, and the sampling time used to generate the flow curves was decreased with increasing shear rate. The average of duplicate measurements is reported.

\section{RESULTS AND DISCUSSION}

\section{Process Scale-up}

The combined cellulose hydrolysis factor $\left(\mathrm{CHF}_{\mathrm{G}}\right.$, where $\mathrm{G}$ denotes glucan or cellulose) and combined delignification factor
(CDF) [Eqs. (S1a) and (S2a)] developed in our earlier studies (Zhu et al., 2012, 2019; Wang et al., 2017) were used to scale-up (750 g OD weight) experiments, rather than using the individual hydrolysis process parameters such as acid concentration, temperature, and time. This is because cellulose depolymerization, predicted by $\mathrm{CHF}_{\mathrm{G}}$ (Eq. S1b; Supplementary Table S1 and Supplementary Figure S1), and delignification, predicted by CDF (Eq. S2b; Supplementary Table S1 and Supplementary Figure S2), are considered critical variables in nanoscale fibrillation of bleached chemicals pulps (Qin et al., 2016; Wang et al., 2017) and raw lignocelluloses (Bian et al., 2017b), respectively. Specifically, we used similar reaction severity (i.e., $\mathrm{CHF}_{\mathrm{G}}$, for $\mathrm{BEP}$ or $\mathrm{CDF}$ for $\mathrm{MDF}$ ) in the scaleup as was found in the lab scale experiments to produce the desired CNM morphology. For example, our earlier labscale study (Wang et al., 2017) indicated that cellulose DP of approximately 250 or lower is required to obtain short, individually separated CNWs from MA-hydrolyzed BEP through mechanical fibrillation. Therefore, pilot-scale runs M1 and M2 as listed in Table 1 were targeted for CNWs with cellulose DP between 200 and 250; runs M3 and M4 were for producing long fibril-network CNFs. For producing lignin-containing CNWs (LCNWs) using $p$-TsOH hydrolysis of MDF, Run P1 (Table 1) was targeted for 50\% delignification; P2 with a lower severity was to explore a lower limit for producing LCNWs. P3 and P4 were for lignin-containing CNFs (LCNFs) with high lignin content and varied morphologies (Supplementary Figure S3).

We observed that increasing reaction temperature from $100^{\circ} \mathrm{C}$ (M2) to $120^{\circ} \mathrm{C}(\mathrm{M} 1)$, or $\mathrm{CHF}_{G}$ from 3.6 (M2) to 37 (M1) (an order of magnitude), resulted in only a small reduction in DP from 223 (M2) to 200 (M1) due to the asymptotic nature of reaching LODP; however, xylan retained on the hydrolyzed solids was reduced from $57 \%$ to $27 \%$ which should facilitate fibrillation.

It is important to note that either $p$-TsOH or MA can be used on bleached fibers for producing CNMs (Chen et al., 2016) or

TABLE 1 | Reaction severity of scale-up runs, predicted final cellulose DP (BEP), residual xylan $X_{R}$ (BEP and MDF) and residual lignin $L_{R}(M D F)$.

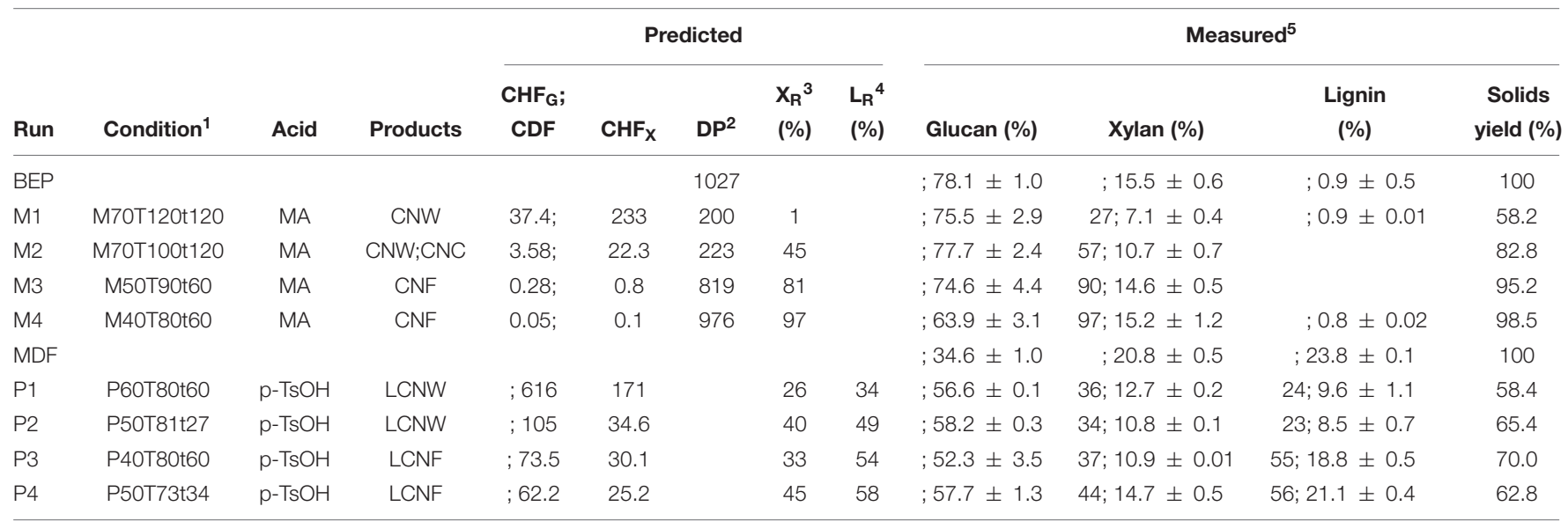

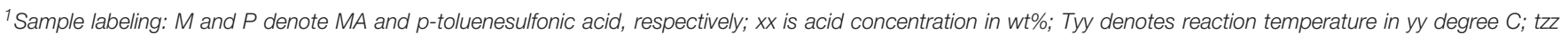

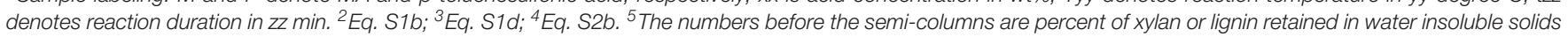

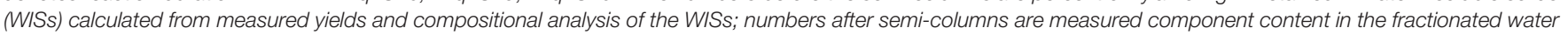
insoluble solids. 
on unbleached fibers for producing LCNMs (Bian et al., 2017a); however, MA cannot delignify the unbleached fibers probably due to extensive lignin condensation, though it is highly effective in solubilizing lignin in untreated wood for producing LCNMs, as recently demonstrated (Cai et al., 2020a,b).

\section{CNM Morphologies}

Morphology of CNMs from scaled-up runs $(750 \mathrm{~g})$ was evaluated by comparing AFM images to those from our earlier published lab-scale (5 g) runs (Wang et al., 2017). Pilot-scale MA-CNCs using severity $\mathrm{CHF}_{\mathrm{G}}=3.58$ (run M2) were similar to, lab-scale severity $\mathrm{CHF}_{\mathrm{G}}=4.08$ demonstrating a successful scale-up, as shown in Figure 2A where I and II designate lab- and pilotscale, respectively.

CNF production was accomplished by mechanical fibrillation of water-insoluble cellulosic solids from MA hydrolysis of BEP fibers. Fibrillation was carried out using a homogenizer for the pilot-scale and a microfluidizer for the lab-scale run for varied passes or extent of fibrillation. Pilot-scale CNFs from severity $\mathrm{CHF}_{\mathrm{G}}=0.28$ (run M3) were also morphologically similar to labscale CNFs from severity $\mathrm{CHF}_{\mathrm{G}}=0.29$ despite differences in their individual hydrolysis conditions, i.e., acid concentration, temperature and reaction time, for example, comparing I.CNF5P with II.CNF-5P shown in Figure 2A (5P stands for 5 passes in fibrillation).

LCNFs from $p$-TsOH fractionation of $\mathrm{MDF}$ were also compared. The higher severity $\mathrm{CDF}=105$ of the pilot-scale run (P2) than the lab-scale run $\mathrm{CDF}=70.8$ was due to a slight overshoot in temperature (Supplementary Figure S4) and a delay in quenching the pilot-scale reaction. As a result, pilot-scale LCNFs had a lignin content of $8.5 \%$ compared with $16 \%$ from the lab-scale run (Bian et al., 2017b). However, morphological similarity between these two runs was achieved simply by applying fewer passes in the homogenizer for the pilot-scale sample, as shown by the AFM images and AFM-measured height distributions (Figure 2B).

After accomplishing scale-up of CNCs, CNFs, and LCNFs, we targeted the primary interest of the present study: CNWs for higher yields with similar morphology to the more crystalline but lower yield CNCs. Figure 3 shows AFM images of (L)CNWs from three high-severity runs: M1, M2, and P1. MA hydrolysis of BEP with subsequent mechanical fibrillation produced individually separated, short whiskers, i.e., CNWs, ranging from 100 to $800 \mathrm{~nm}$ in length, with only a single pass through homogenization. Continued fibrillation further reduced aggregations and diameters of the whiskers, resulting in more uniform dimensions. Short and individually separated, lignin-containing LCNWs were obtained after one pass homogenization of the fractionated MDF under P1. However, a sample aliquot after three passes showed significantly longer fibrils, which strongly suggests that P1 condition is not severe enough, or lacking sufficient cellulose depolymerization, to reduce all the fibrils into LCNWs, which will be the topic of future study.

The morphology of pilot-scale CNWs was compared to $\mathrm{S}-\mathrm{CNCs}$ and CNCs from MA hydrolysis as shown in Figure 3. CNWs from the most severe condition (M1-3P) resembled the
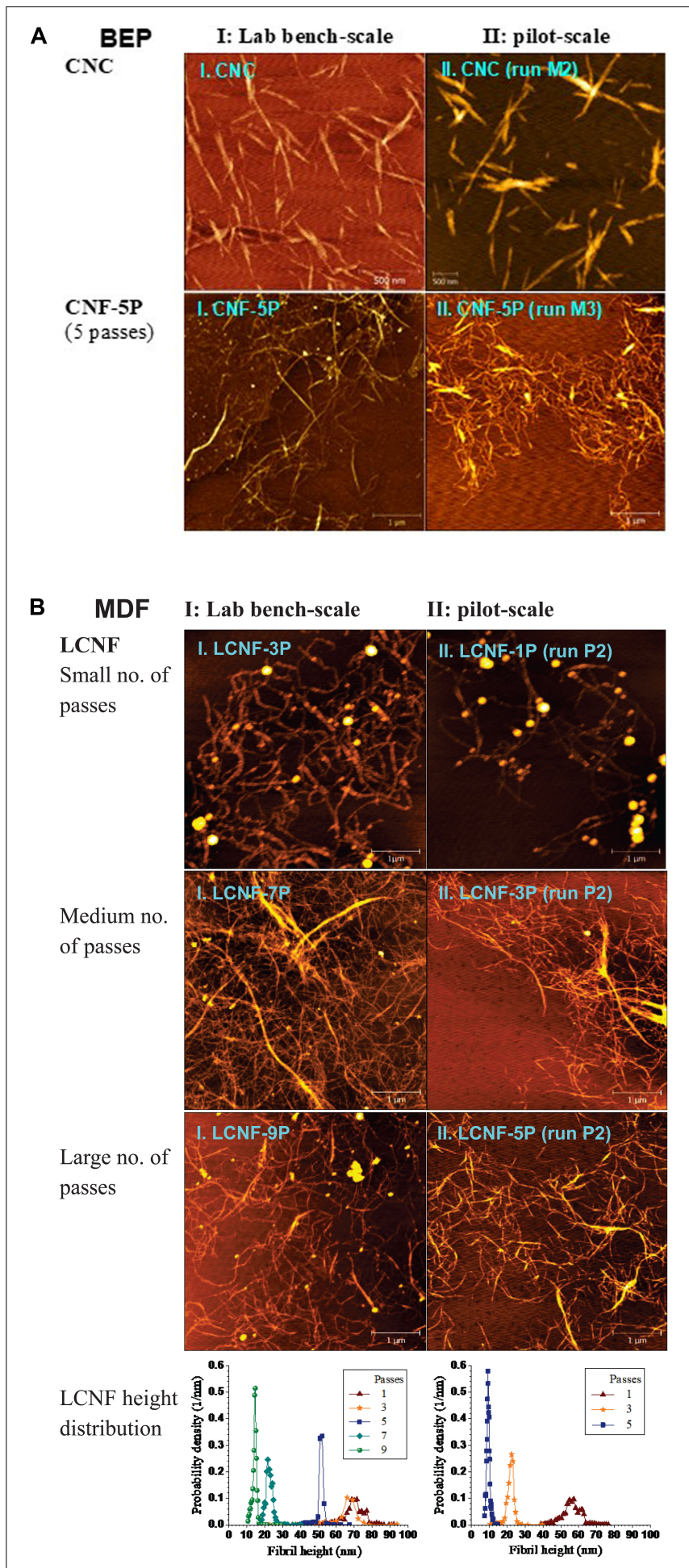

FIGURE 2 | Morphological comparisons of CNMs between samples from lab bench-scale (5 g oven dry weight) runs (I, left panel) and corresponding pilot-scale (750 g) runs (II, right panel). (A): CNC and CNF from BEP using $\mathrm{MA}$; I.CNC: $\mathrm{CHF}_{\mathrm{G}}=4.08$, I.CNF: $\mathrm{CHF}_{\mathrm{G}}=0.29,5$ passes; II.CNC: $\mathrm{CHF}_{\mathrm{G}}=3.58$, I. CNF: $\mathrm{CHF}_{\mathrm{G}}=0.28,5$ passes. $(\mathbf{B})$ : LCNF from MDF using $\mathrm{p}-\mathrm{TsOH}$ with varying numbers of passes through fibrillation. I.LCNF: $\mathrm{CDF}=70.8$, 3-9 passes, II.LCNF: CDF $=105,1-5$ passes. Detailed reaction conditions are listed in Table $\mathbf{1 .}$ 


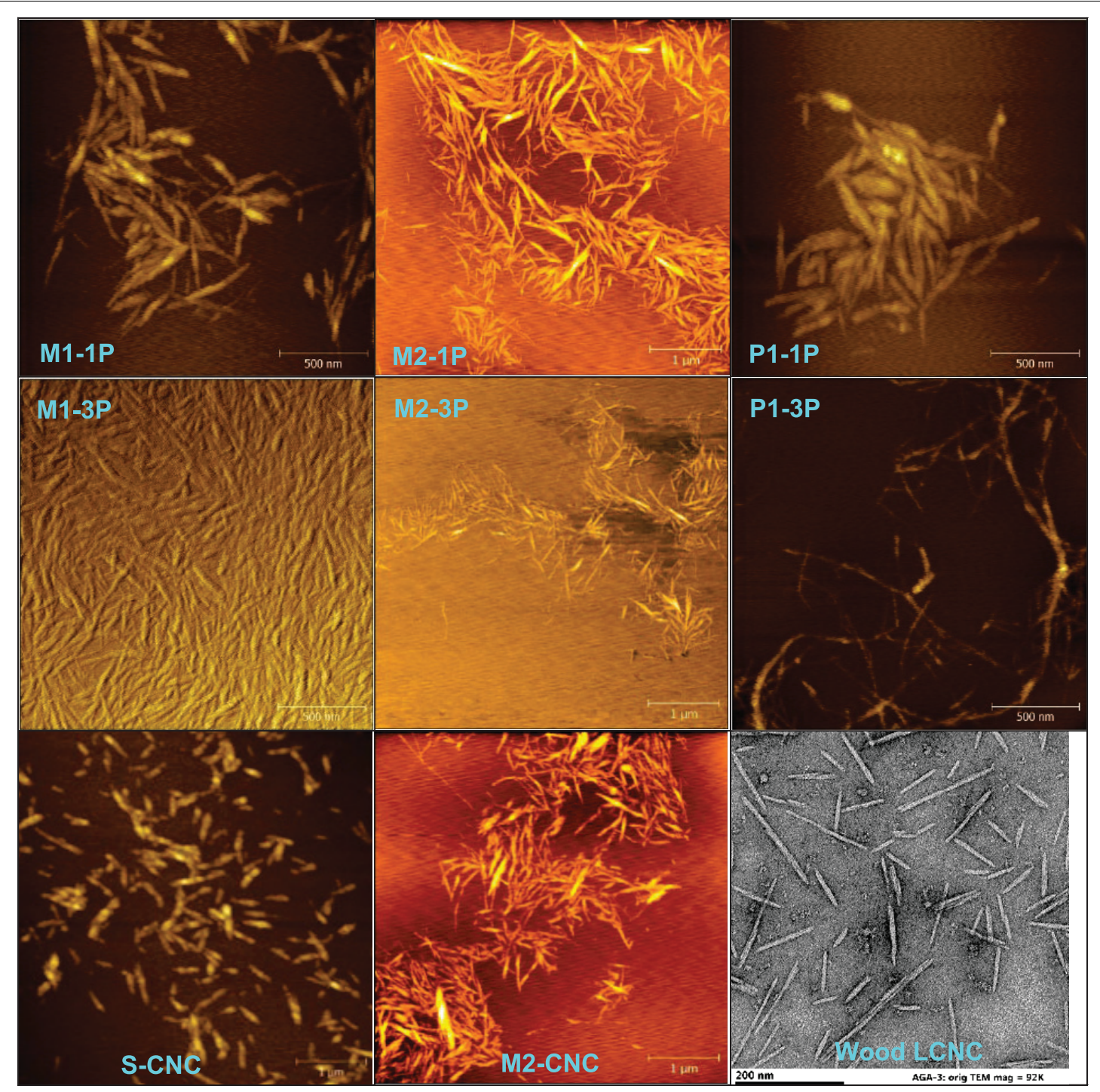

FIGURE 3 | AFM images of CNWs from three high severity pilot-scale runs (M1, M2, and P1) with varied passes (-xP) of homogenization (top and middle rows), S-CNCs (bottom left), CNCs from maleic acid hydrolysis (bottom middle) and LCNCs from sulfuric acid hydrolysis of poplar wood (bottom right).

S-CNCs except longer, i.e., $365 \mathrm{vs.} 185 \mathrm{~nm}$ and aspect ratio 12.2 vs. 7.7 (Supplementary Table S2), respectively; CNWs from less severe conditions (M2-1P) were very similar to the MA-CNCs separated from this run by dialysis, i.e., 325 vs. $240 \mathrm{~nm}$ and aspect ratio 11.6 vs. $9.2 \mathrm{~nm}$ (Supplementary Table S2). The pilotscale LCNWs (P1-1P) were both longer and thicker than LCNCs obtained from direct concentrated sulfuric acid hydrolysis of Wiley-milled poplar wood (Agarwal et al., 2018), i.e., 430 vs. $125 \mathrm{~nm}$ and 40 vs. $9 \mathrm{~nm}$ (Supplementary Table S2).

\section{Post-fibrillation Enzymatic Treatment}

Post-fibrillation enzymatic treatment can be an effective way to reduce fibril aggregations for producing $\mathrm{CNW}$ s with low environmental impact. Two fibrillated CNM samples (M2-3P and $\mathrm{M} 3-5 \mathrm{P}$ ) were enzymatically treated using a commercial endoglucanase, FiberCare ${ }^{\circledR}$, at very low loadings of 0.2 and
$0.4 \mathrm{mg}$ protein/g CNFs, respectively. The results (Figure 4) clearly indicate the effectiveness of endoglucanase treatments to reduce aggregation, diameter, entanglement and length of CNMs. At a lower endoglucanase loading of $0.2 \mathrm{mg} / \mathrm{g}$, M2-3P became much more uniform in diameter with only $4 \mathrm{~h}$ of enzymatic treatment (based on AFM measured topographic height distribution, comparing M2-3P with M23P-E4h). The average AFM measured fibril height was also reduced from approximately $16 \mathrm{~nm}$ to $13 \mathrm{~nm}$. Extended treatment to $48 \mathrm{~h}$ (M2-3P-E48h) did not substantially impact the morphology, suggesting potential accessible sites, such as dislocations and disorder regions, have been effectively digested during the shorter period treatment which left fairly uniform and ordered CNW.

Similar effectiveness was also observed for M3-5P with a fibril network morphology but with a similar height of approximately 


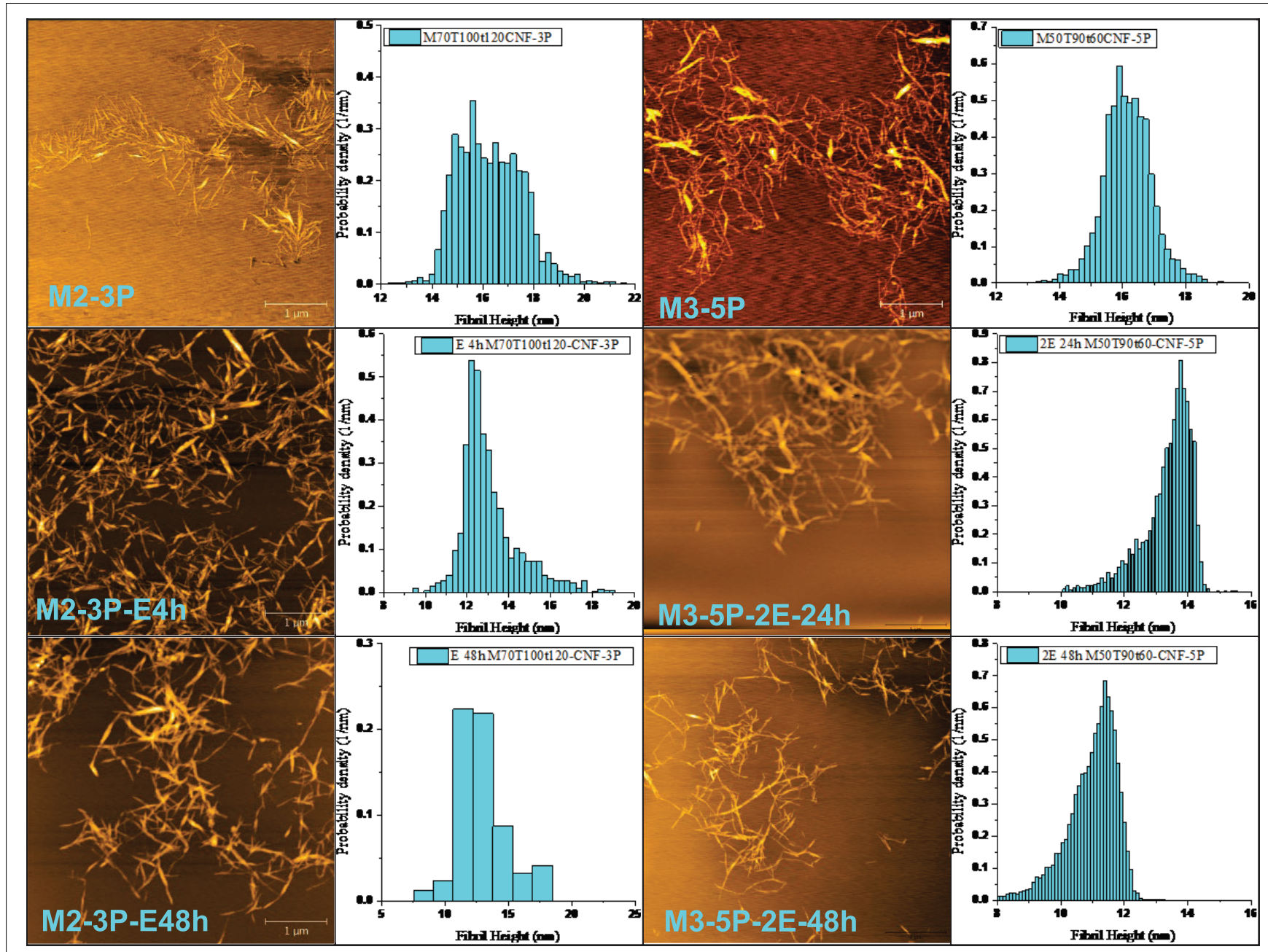

FIGURE 4 | CNM morphological changes through post-fibrillation endoglucanase treatments. FiberCare loading in mg protein/g CNMs: $\mathrm{E}=0.2$ and $2 \mathrm{E}=0.4$ for sample M2-3P and M3-5P, respectively. Treatment time: $4-48 \mathrm{~h}$.

TABLE 2 | Effect of mechanical fibrillation levels on Crl of CNMs.

\begin{tabular}{|c|c|c|c|c|c|c|c|}
\hline \multirow[b]{2}{*}{ Run \# } & \multirow[b]{2}{*}{ Hydrolysis condition } & \multicolumn{2}{|c|}{ Segal-I } & \multicolumn{2}{|c|}{ Segal-II } & \multicolumn{2}{|c|}{ 380-Raman } \\
\hline & & $1 P$ & $3 P$ & $1 P$ & $3 P$ & $1 P$ & $3 P$ \\
\hline M1 & M70T120t120 & 89.1 & 85.1 & 77.6 & 74.0 & $51.7 \pm 2.0$ & $42.5 \pm 1.0$ \\
\hline M4 & M40T80t60 & 85.0 & 84.3 & 72.9 & 72.3 & $47.6 \pm 1.4$ & $42.1 \pm 1.0$ \\
\hline P1 & P60T80t60 & 82.0 & 81.6 & 68.1 & 67.0 & $N A^{*}$ & $N A^{*}$ \\
\hline P3 & P40T80t60 & 81.8 & 77.8 & 67.5 & 64.2 & $N A^{*}$ & $N A^{*}$ \\
\hline
\end{tabular}

*Not available; could not be estimated due to fluorescence signal in the Raman spectra.

$16 \mathrm{~nm}$ (3rd and 4th columns in Figure 4). With a double endoglucanase loading of $0.4 \mathrm{mg} / \mathrm{g}$, the sample network was effectively broken down after $48 \mathrm{~h}$ treatment (M3-5P-2E48h). The CNM average height was reduced to approximately 13 and $11 \mathrm{~nm}$ after 24 and $48 \mathrm{~h}$ treatment, respectively. These results suggest that post-fibrillation enzymatic treatment can be an effective tool to modify CNM morphologies for producing individually separated CNWs, or substantially less entangled
CNFs, in agreement with literature (Henriksson et al., 2007; Pääkko et al., 2007; Zhu et al., 2011; Wang et al., 2015, 2016; Yarbrough et al., 2017).

\section{Crystallinity}

Crystallinity index (CrI) of selected samples was measured by both Raman spectroscopy (380-Raman) and X-ray diffraction (Segal methods I and II, with and without background 
subtraction, respectively) as listed in Table 2. Segal II CrI for M1-1P (77.6\%) and M1-3P (74.0\%) are lower than that reported for CNCs (81\%) produced from concentrated oxalic acid hydrolysis of the same BEP (Chen et al., 2016), but equivalent to that reported for S-CNCs from the same BEP (Chen et al., 2015). In this sense, the high-severity (M1) product could be called CNCs, though not a product of strong acid hydrolysis and dialysis. In contrast to the insensitivity of the Segal method to changes in crystallinity, the 380-Raman method indicated a much larger reduction in CrI (18\% vs. 5\%) upon homogenization, thereby suggesting these materials should be called CNWs rather than CNCs.

The reduction of crystallinity by extensive mechanical fibrillation was also confirmed from Raman measurements. Raman $\mathrm{CH}_{2}$ bands at 1481 and $1462 \mathrm{~cm}^{-1}$ have been attributed to crystalline and disordered celluloses, respectively (Schenzel et al., 2005). As shown in Figure 5, the $\mathrm{CH}_{2}$ band shifted from 1472 to $1468 \mathrm{~cm}^{-1}$ in $\mathrm{M} 1$ going from 1 to 3 pass homogenization (i.e., M1-1P to M1-3P). A similar but smaller shift (1469 to $1467 \mathrm{~cm}^{-1}$ ) was observed in samples from less severe hydrolysis (i.e., M4-1P to M4-3P).

Another confounding factor with CNM classification via crystallinity measurement is illustrated with the less severity samples P1 and P3, where unlike the M1 sample with low xylan and near-zero lignin content (Table 1), the presence of hemicelluloses and/or lignin obscures the reduction of CrI after more homogenization, as shown in Table 2.

\section{Thermal Stability Analyses}

Thermogravimetric analyses (TGA) indicate CNWs M1-1P and M1-3P have good thermal stability. The onset of degradation, as defined as $d W / d T \geq-1$, was at approximately $247^{\circ} \mathrm{C}$ and $252^{\circ} \mathrm{C}$, respectively, as shown in Figure 6. These values are lower than $301^{\circ} \mathrm{C}$ for MA-CNCs produced at M60T100t45 reported previously, but notably higher than $218^{\circ} \mathrm{C}$ for S-CNCs (Chen et al., 2016).

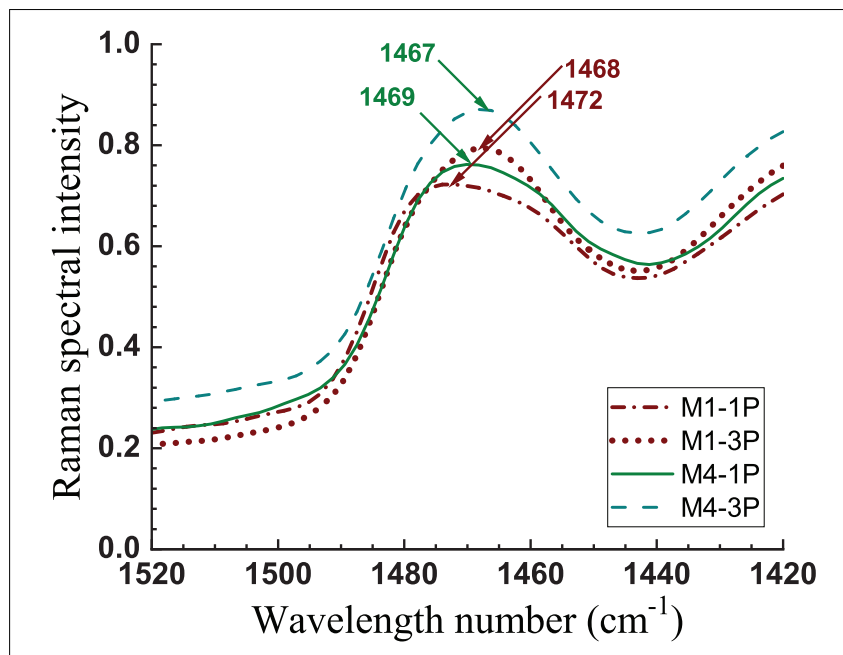

FIGURE 5 | Raman spectra of two sets of CNMs showing the $\mathrm{CH}_{2}$ band shifts with increased mechanical fibrillation (1 pass to 3 passes homogenization).

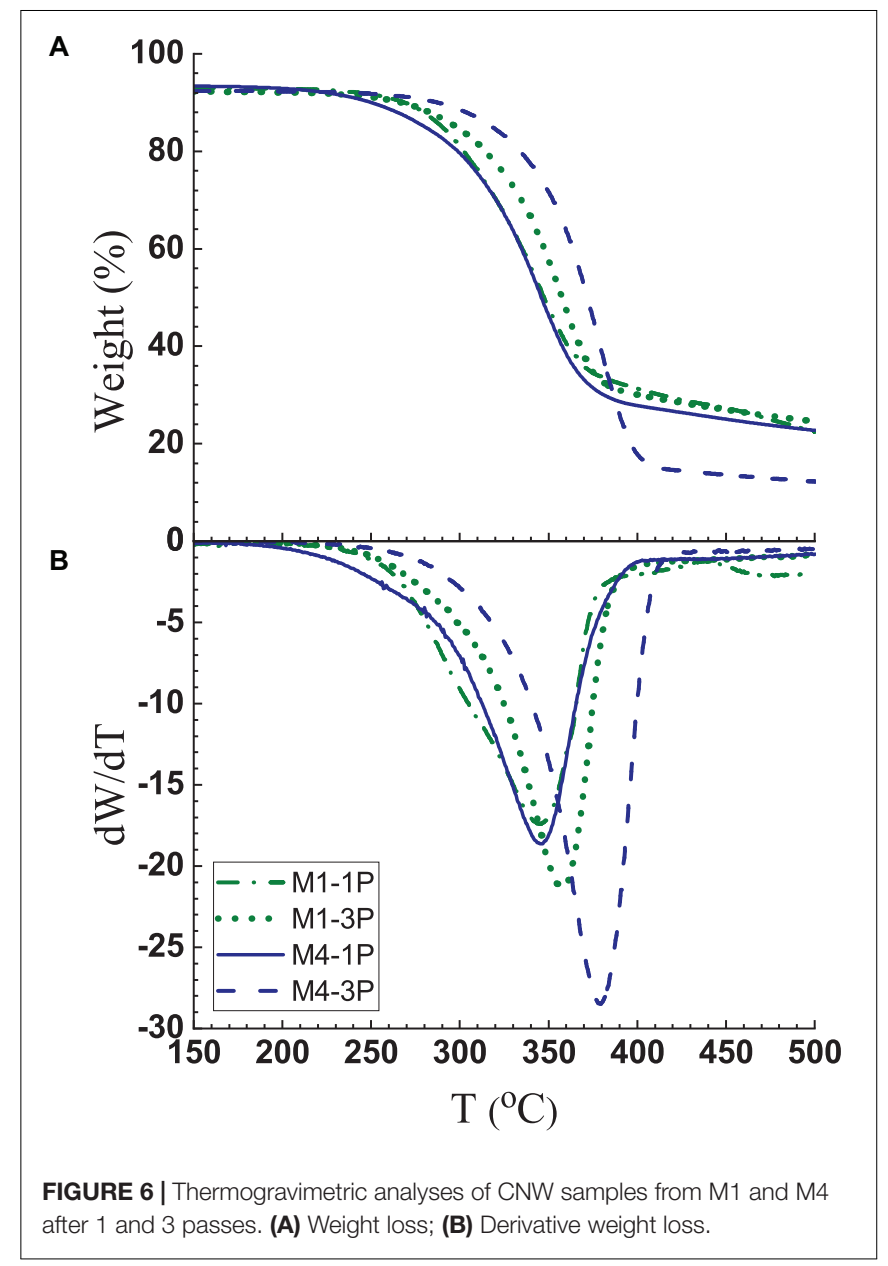

It is interesting to notice that increasing fibrillation from one pass to three passes through homogenization increased thermal stability for both M1 CNWs and M4 CNFs. This is perhaps due to the increased exposure of hydroxyl groups with more fibrillation. Homogenization is primarily a shearing action that fibrillates, rather than cuts, cellulose fibrils resulting in minimal cellulose depolymerization. This can be seen from the DP data listed in Table 3, as well as from the sample morphologies shown in AFM images in Figure 3 and Supplementary Figure S3. The temperature shift at maximal weight loss is due to increased fibrillation and, as shown in Figure $\mathbf{6 B}$, was obvious for both CNMs from M1 and M4. Therefore, we confidently demonstrate that reduction in thermal stability due to depolymerization is low.

\section{Surface Properties}

Surface functionalization and charge are important properties to dispersion. M2-CNCs had more than double the carboxyl group content than the corresponding CNWs M2-1P and M2-3P (0.25, 0.11 and $0.13 \mathrm{mmol} / \mathrm{g}$, respectively), as shown in Table 3 and in agreement with our earlier lab-scale study (Chen et al., 2016); and the higher-severity M1-CNWs had a greater carboxyl group content $(\geq 0.25 \mathrm{mmol} / \mathrm{g})$ than the M2-CNWs, as expected. 
TABLE 3 | Surface charge and carboxyl group content along with dynamic light scattering (DLS) measured size and degree of polymerization of CNM samples listed in Table 1.

\begin{tabular}{lcccc}
\hline CNM Label & $\begin{array}{c}\text { Zeta-potential } \\
(\mathbf{m} \mathbf{)})\end{array}$ & $\begin{array}{c}\text { DLS size } \\
\mathbf{( n m )}\end{array}$ & $\begin{array}{c}\text { Carboxyl content } \\
(\mathbf{m m o l} / \mathbf{g})\end{array}$ & DP \\
\hline M1-1P & $-33.5 \pm 1.1$ & $693 \pm 42$ & 0.250 & $203 \pm 0$ \\
M1-3P & $-44.5 \pm 1.6$ & $649 \pm 33$ & 0.270 & $178 \pm 1$ \\
M2-CNC & $-37.5 \pm 0.5$ & $629 \pm 25$ & 0.252 & N/A * \\
M2-1P & $-34.1 \pm 1.6$ & $712 \pm 52$ & 0.113 & N/A * \\
M2-3P & $-56.6 \pm 0.6$ & $678 \pm 46$ & 0.129 & $177 \pm 3$ \\
M3-1P & $-32.5 \pm 1.0$ & & 0.011 & $372 \pm 1$ \\
M3-3P & $-48.4 \pm 2.8$ & & 0.016 & $331 \pm 2$ \\
M4-1P & $-30.6 \pm 3.6$ & & & $683 \pm 8$ \\
M4-3P & $-30.0 \pm 1.8$ & & & \\
P1-1P & $-30.7 \pm 3.6$ & & & \\
P1-3P & $-31.8 \pm 2.9$ & & & \\
P3-1P & $-27.4 \pm 2.2$ & & & \\
P3-3P & $-31.7 \pm 2.6$ & & &
\end{tabular}

*Not analyzed due to limited sample available.

M1-1P and M2-1P had surface charge similar level to M2$\mathrm{CNC}(-33.5,-34.1$, and $-37.5 \mathrm{mV}$, respectively). Increasing mechanical fibrillation increased surface charge for both M1-3P and M2-3P to approximately $-45 \mathrm{mV}$ or higher. These numbers suggest that CNWs from M1 and M2 through mechanical fibrillation are just as easily dispersible as M2-CNC.

Further reduction of hydrolysis severity decreased carboxylation as expected (Chen et al., 2016), as can be seen from M3 and M4 samples. Notably, however, despite the very low carboxyl content of only approximately $0.01 \mathrm{mmol} / \mathrm{g}$, surface charge exceeds $-30 \mathrm{mV}$, which is sufficient for dispersion. This suggests that surface charge is affected not only by carboxyl groups but also by hydroxyl groups. With three passes through homogenization, surface charge was increased to over $-45 \mathrm{mV}$ for both M2-3P and M3-3P.

Similarly, LCNF samples are also charged, but lower than the MA-produced CNM samples (Table 3). This is because $\mathrm{p}-\mathrm{TsOH}$ does not functionalize fibers. Surface charges of LCNFs from P1 and P3 treatments were below $-30 \mathrm{mV}$. As was the case before, surface charge increased with more fibrillation.

\section{Aqueous Suspension Rheology}

As shown in Figures 7A-C, the S-CNC suspensions have typical semi-diluted CNC suspension rheology behavior up to $3 \mathrm{wt} \%$, as also indicated in literature (Orts et al., 1998; de Souza Lima and Borsali, 2004; Oguzlu et al., 2017), i.e., shear thinning at low shear rates, a plateau region at moderate shear rates, then shear thinning again at high shear rates. CNW M1-3P at $0.5 \mathrm{wt} \%$ concentration (Figure $7 \mathbf{A}$ ) also shows semi-diluted suspension behavior. As a matter of fact, its viscosity vs. shear rate curve almost overlaps with the curve for S-CNCs. However, at $1.5 \mathrm{wt} \%, \mathrm{M} 1-3 \mathrm{P}$ behaves similar to concentrated S-CNC suspension, as reported in the literature (Bercea and Navard, 2000; Shafiei-Sabet et al., 2012, 2014), i.e., viscosities decreased linearly with increased shear rate.
Compared with the S-CNCs with a mean aspect ratio of 7.7, CNW M1-3P has a greater aspect ratio of 12.2 (Supplementary Table S3). As a result, M1-3P has a greater range of viscosity within a very narrow concentration range under the same shear rate. For example, M1-3P viscosity increased over three orders of magnitude at a low shear rate of $0.11 / \mathrm{s}$ when suspension concentration was increased from $0.5 \mathrm{wt} \%$ to 1.5 $\mathrm{wt} \%$ as shown in Figure 7D. There is essentially no change in viscosity for S-CNCs. At a moderate shear rate of 10 1/s, M1$3 \mathrm{P}$ viscosity increased approximately three orders of magnitude, much greater than the increase for S-CNCs when concentration was increased from $0.5 \mathrm{wt} \%$ to $1.5 \mathrm{wt} \%$ (Figure 7E). Even at a high shear rate of $10001 / \mathrm{s}, \mathrm{M} 1-3 \mathrm{P}$ viscosity increased approximately one order of magnitude but S-CNCs viscosity had negligible increase when concentration was increased from $0.5 \mathrm{wt} \%$ to $3 \mathrm{wt} \%$ (Figure $7 \mathbf{F}$ ). This indicates that $\mathrm{CNW}$ M1-3P can be a much more effective rheology modifier than S-CNCs.

The two lignin-containing LCNMs showed some interesting rheological behavior. First, CNF P3-3P, which has a higher lignin content of $18.8 \%$ than the $9.6 \%$ of P1-3P (Table 1), has a lower viscosity under the same shear rate at the same suspension concentration, despite having much more entangled fibril networks (Supplementary Figure S3) than P13P (Figure 3). This indicates that lignin as a hydrophobic molecule plays a significant role in the rheological properties of aqueous lignin-containing CNF suspension, primarily due to limiting interactions with water. Second, it appears that both suspensions have a plateau region at suspension concentration below $1.5 \mathrm{wt} \%$ (Figures 7A,B). At $3 \mathrm{wt} \%$, this plateau disappears (Figure 7C) and viscosity decreased linearly with shear rate, similar to concentrated CNC suspension. Due to their fibril network morphology (Figure 3 and Supplementary Figure S3), these two LCNM suspensions have relatively large viscosity ranges, as shown in Figures $7 \mathbf{D}-\mathbf{F}$. However, their ranges are smaller to the viscosity range of M1-3P except at very high shear rates (Figure 7F). Overall, the rheology properties of these two suspensions were very similar.

\section{Applications of CNWs and Final Thoughts}

The CNWs from M2-3P (Figure 3) were used for producing unsaturated polyester resin (UPR) nanocomposite, though incorrectly labeled in the study (DiLoreto et al., 2019). It was demonstrated that freeze-dried M2-3P can be directly used to reinforce UPR and resulted in $61 \%$ and $48 \%$ increase in glassy and rubbery modulus, respectively, over the UPR baseline; and glass transition temperature was increased by $12^{\circ} \mathrm{C}$. Using S-CNCs decreased UPR nanocomposite tensile strength. Equivalent gains in glassy and rubbery modulus were achieved only after modifying S-CNCs using methyl(triphenyl) phosphonium; however, this resulted in only a $4.5^{\circ} \mathrm{C}$ gain in glass transition temperature.

Based on the rheology data presented here, we see CNWs being particularly suitable for rheology modification and 3D printing. In this study, we demonstrated scale-up production 

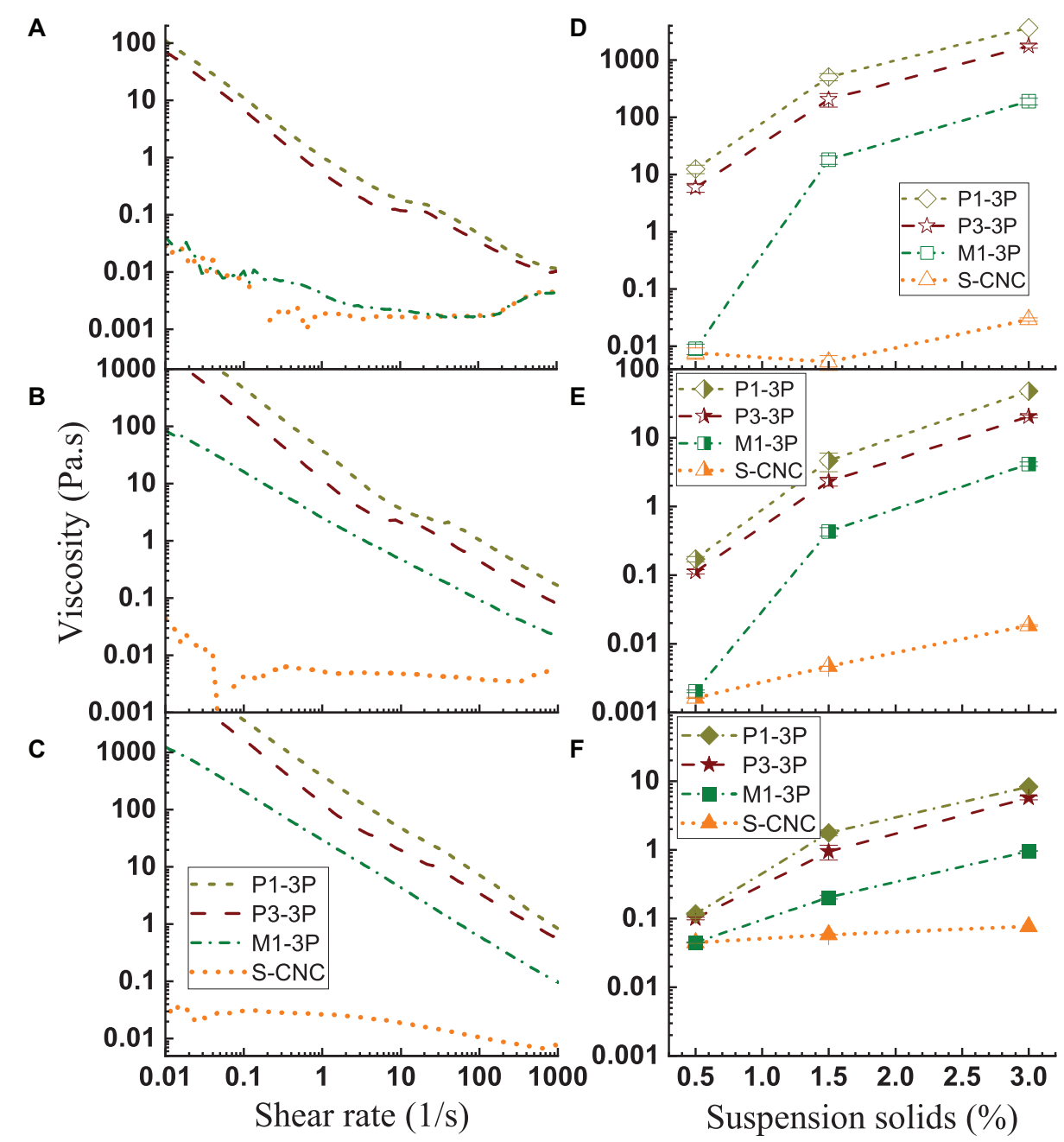

FIGURE 7 | Effects of shear rate and CNM solids loading on CNM suspension viscosity. Left column: Solids loadings = 0.5 wt\% (A); 1.5 wt\% (B); 3.0 wt\% (C). Right column: Shear rate $=0.11 / \mathrm{s}$ (D); $101 / \mathrm{s}(\mathbf{E}) ; 10001 / \mathrm{s} \mathbf{( F )}$.

with good control of sample morphology. Because MA is a solid acid with a relatively low solubility at room temperature, solidification to partially recover acid can be readily achieved (Chen et al., 2016; Cai et al., 2020a). Using mature technology, the remaining acid can be used to dehydrate the dissolved xylose to furfural at elevated temperatures (Cai et al., 2020a). When commercial bleached pulp fibers are used, the spent liquor is fairly clean after furfural dehydration and distillation and can be simply reused (Cai et al., 2020a). By producing CNWs with morphological and surface charge properties similar to those of CNCs but without dialysis, we can substantially reduce water usage to achieve sustainable production with favorable yields.

\section{CONCLUSION}

This study describes a class of cellulosic nanomaterials produced at pilot-scale using maleic acid, an easily recyclable solid dicarboxylic acid and FDA approved indirect food additive per code of federal regulation 21CFR175-177, hydrolysis with subsequent mechanical nanoscale fibrillation, which we call cellulosic nanowhiskers (CNWs). Although crystallinity is not required in classifying CNWs, we characterized crystallinity, along with morphology, surface properties, and suspension rheology. We demonstrated some applications in which CNWs outperform the more expensive crystalline S-CNCs. We clarified why CNCs should not be used for applications that do not require crystalline property, such as rheology modifiers and 3D printings. By both Raman spectroscopy and X-Ray diffraction measurements, we demonstrated the reduction in crystallinity of CNMs with mechanical fibrillation. We therefore put forth the argument that CNWs should not be termed CNCs, although CNWs such as those from MA hydrolysis, can be crystalline with very similar morphology and surface charge to CNCs. Furthermore, we demonstrated that the surface carboxylated CNWs produced from maleic acid hydrolysis have good surface charge of $-35 \mathrm{mV}$ or higher that facilitated dispersion suitable 
for a variety of applications to substitute CNCs. Both CNW and lignin-containing LCNW suspensions, within a very narrow concentration range, exhibit a wide range of viscosity 0.001 to 1000 Pa.s under a range of shear rates for better performance as a rheological modifier compared to the viscosity of $0.001-0.1$ Pa.s of traditional sulfuric acid S-CNCs. Finally, the scale-up showed good control of product morphology.

\section{DATA AVAILABILITY STATEMENT}

All datasets presented in this study are included in the article/Supplementary Material.

\section{AUTHOR CONTRIBUTIONS}

HW conducted CNM characterization including AFM, carboxyl group and surface charge, and CNM suspension rheology. JJZ conducted post-fibrillation enzymatic treatment and AFM of the treated samples. QM conducted fractionation studies to develop scale-up factors. UA conducted Raman scattering characterization and crystallinity analyses. RG and RR conducted pilot-scale CNMs and S-CNC production. CB conducted $\mathrm{x}$-ray crystallinity measurements. JYZ initiated the research and wrote

\section{REFERENCES}

Agarwal, U. P., Ralph, S. A., Reiner, R. S., Hunt, C. G., Baez, C., Ibach, R., et al. (2018). Production of high lignin-containing and lignin-free cellulose nanocrystals from wood. Cellulose 25, 5791-5805. doi: 10.1007/s10570-0181984-z

Agarwal, U. P., Reiner, R. S., and Ralph, S. A. (2010). Celulose I crystallinity determination using FT-Raman spectroscopy: univariate and multivariate methods. Cellulose 17, 721-733. doi: 10.1007/s10570-0109420-z

Agarwal, U. P., Zhu, J. Y., and Ralph, S. A. (2013). Enzymatic hydrolysis of loblolly pine: effects of cellulose crystallinity and delignification. Holzforschung 67, 371-377. doi: 10.1515/hf-2012-0116

Anderson, S. R., Esposito, D., Gillette, W., Zhu, J. Y., Baxa, U., and McNeil, S. E. (2014). Enzymatic preparation of nanocrystalline and microcrystalline cellulose. TAPPI J. 13, 35-41. doi: 10.32964/tj13.5.35

Battista, O. A. (1950). Hydrolysis and crystallization of cellulose. Industry Eng. Chem. 42, 502-507. doi: 10.1021/ie50483a029

Battista, O. A., Coppicic, S., Howsmon, J. A., Morehead, F. F., and Sisson, W. A. (1956). Level-off degree of polymerization: relation to polyphase structure of cellulose fibers. Ind. Eng. Chem. 48, 333-335.

Bercea, M., and Navard, P. (2000). Shear dynamics of aqueous suspensions of cellulose whiskers. Macromolecules 33, 6011-6016. doi: 10.1021/ma00 $0417 \mathrm{p}$

Bian, H., Chen, L., Dai, H., and Zhu, J. Y. (2017a). Integrated production of lignin containing cellulose nanocrystals (LCNC) and nanofibrils (LCNF) using an easily recyclable di-carboxylic acid. Carbohyd. Polym. 167, 167-176. doi: 10.1016/j.carbpol.2017.03.050

Bian, H., Chen, L., Gleisner, R., Dai, H., and Zhu, J. Y. (2017b). Producing wood-based nanomaterials by rapid fractionation of wood at $80^{\circ} \mathrm{C}$ using a recyclable acid hydrotrope. Green Chem. 19, 3370-3379. doi: 10.1039/c7gc 00669a

Braun, B., and Dorgan, J. R. (2009). Single-step method for the isolation and surface functionalization of cellulosic nanowhiskers. Biomacromolecules 10, 334-341. doi: $10.1021 / \mathrm{bm} 8011117$ most of the manuscript. All authors contributed to the article and approved the submitted version.

\section{FUNDING}

This work was conducted at the USDA Forest Products Lab (FPL) while HW was a visiting scientist under the sponsorship of Guangzhou Elite Project of China and a China Science Foundation Postdoctoral Fellowship (2019TQ0102).

\section{ACKNOWLEDGMENTS}

We acknowledge Dr. Ronald Zalesny, Jr. of Institute for Applied Ecosystem Studies of the USDA Forest Service, Northern Research Station for providing birch wood logs for the study. We also acknowledge Kolby Hirth of FPL for many helpful discussions and suggestions.

\section{SUPPLEMENTARY MATERIAL}

The Supplementary Material for this article can be found online at: https://www.frontiersin.org/articles/10.3389/fbioe. 2020.565084/full\#supplementary-material

Cai, C., Hirth, K., Gleisner, R., Lou, H., Qiu, X., and Zhu, J. Y. (2020a). Maleic acid as a dicarboxylic acid hydrotrope for sustainable fractionation of wood at atmospheric pressure and $\leq 100^{\circ} \mathrm{C}$ : mode and utility of lignin esterification. Green Chem. 22, 1605-1617. doi: 10.1039/C9GC04267A

Cai, C., Li, J., Hirth, K., Huber, G. W., Lou, H., and Zhu, J. Y. (2020b). Comparison of two acid hydrotropes for sustainabl fractionation of birch wood. Chemsuschem 13. doi: 10.1002/cssc.202001120

Chen, L., Wang, Q., Hirth, K., Baez, C., Agarwal, U. P., and Zhu, J. Y. (2015). Tailoring the yield and characteristics of wood cellulose nanocrystals (CNC) using concentrated acid hydrolysis. Cellulose 22, 1753-1762. doi: 10.1007/ s10570-015-0615-1

Chen, L., Zhu, J. Y., Baez, C., Kitin, P., and Elder, T. (2016). Highly thermalstable and functional cellulose nanocrystals and nanofibrils produced using fully recyclable organic acids. Green Chem. 18, 3835-3843. doi: 10.1039/c6gc $00687 \mathrm{f}$

De France, K. J., Badv, M., Dorogin, J., Siebers, E., Panchal, V., Babi, M., et al. (2019). Tissue response and biodistribution of injectable cellulose nanocrystal composite hydrogels. ACS Biomater. Sci. Eng. 5, 2235-2246. doi: 10.1021/ acsbiomaterials.9b00522

de Souza Lima, M. M., and Borsali, R. (2004). Rodlike cellulose microcrystals: structure, properties, and applications. Macromol. Rapid Commun. 25, 771-787. doi: 10.1002/marc.200300268

DiLoreto, E., Haque, E., Berman, A., Moon, R. J., and Kalaitzidou, K. (2019). Freeze dried cellulose nanocrystal reinforced unsaturated polyester composites: challenges and potential. Cellulose 26, 4391-4403. doi: 10.1007/s10570-01902377-1

Grishkewich, N., Mohammed, N., Tang, J., and Tam, K. C. (2017). Recent advances in the application of cellulose nanocrystals. Curr. Opin. Coll. Interf. Sci. 29, 32-45. doi: 10.1016/j.cocis.2017.01.005

Hausmann, M. K., Rühs, P. A., Siqueira, G., Läuger, J., Libanori, R., Zimmermann, T., et al. (2018). Dynamics of cellulose nanocrystal alignment during 3D printing. ACS Nano 12, 6926-6937. doi: 10.1021/acsnano.8b 02366

Henriksson, M., Henriksson, G., Berglund, L. A., and Lindström, T. (2007). An environmentally friendly method for enzyme-assisted preparation of 
microfibrillated cellulose (MFC) nanofibers. Eur. Polym. J. 43, 3434-3441. doi: 10.1016/j.eurpolymj.2007.05.038

Hirota, M., Furihata, K., Saito, T., Kawada, T., and Isogai, A. (2010). Glucose/glucuronic acid alternating co-polysaccharides prepared from TEMPO-oxidized native celluloses by surface peeling. Angew. Chem. Intern. Edn. 49, 7670-7672. doi: 10.1002/anie.201003848

Hou, K., Li, Y., Liu, Y., Zhang, R., Hsiao, B. S., and Zhu, M. (2017). Continuous fabrication of cellulose nanocrystal/poly(ethylene glycol) diacrylate hydrogel fiber from nanocomposite dispersion: rheology, preparation and characterization. Polymer 123, 55-64. doi: 10.1016/j.polymer.2017. 06.034

Jeon, C. H., Makhaeva, E. E., and Khokhlov, A. R. (1999). Complexes of polyelectrolyte hydrogels with organic dyes: effect of charge density on the complex stability and intragel dye aggregation. J. Polym. Sci. Part B Polym. Phys. 37, 1209-1217. doi: 10.1002/(sici)1099-0488(19990615)37:12<1209::aidpolb2>3.0.co; $2-\mathrm{x}$

Jia, C., Bian, H., Gao, T., Jiang, F., Kierzewski, I. M., Wang, Y., et al. (2017). Thermally stable cellulose nanocrystals toward high-performance $2 \mathrm{D}$ and $3 \mathrm{D}$ nanostructures. ACS Appl. Mater. Interf. 9, 28922-28929. doi: 10.1021/acsami. $7 \mathrm{~b} 08760$

Kim, D., Park, S., Jo, I., Kim, S. M., Kang, D. H., Cho, S. P., et al. (2017). Multiscale modulation of nanocrystalline cellulose hydrogel via nanocarbon hybridization for 3D neuronal bilayer formation. Small 13:1700331. doi: 10 . 1002/smll.201700331

Larsson, P. T., Wickholm, K., and Iversen, T. (1997). A CP/MAS 13 C NMR investigation of molecular ordering in celluloses. Carbohyd. Res. 302, 19-25. doi: 10.1016/s0008-6215(97)00130-4

Leung, A. C. W., Hrapovic, S., Lam, E., Liu, Y., Male, K. B., Mahmoud, K. A., et al. (2011). Characteristics and properties of carboxylated cellulose nanocrystals prepared from a novel one-step procedure. Small 7, 302-305. doi: 10.1002/smll. 201001715

Li, V. C. F., Kuang, X., Mulyadi, A., Hamel, C. M., Deng, Y., and Qi, H. J. (2019). $3 \mathrm{D}$ printed cellulose nanocrystal composites through digital light processing. Cellulose 26, 3973-3985. doi: 10.1007/s10570-019-02353-9

Luo, X., Gleisner, R., Tian, S., Negron, J., Horn, E., Pan, X. J., et al. (2010). Evaluation of mountain beetle infested lodgepole pine for cellulosic ethanol production by SPORL pretreatment. Ind. Eng. Chem. Res. 49, 8258-8266. doi: $10.1021 /$ ie 1003202

Mark, R. E. (1967). Cell Wall Mechanics and Tracheids. London: Yale University Press.

Molnes, S. N., Mamonov, A., Paso, K. G., Strand, S., and Syverud, K. (2018). Investigation of a new application for cellulose nanocrystals: a study of the enhanced oil recovery potential by use of a green additive. Cellulose 25, 22892301. doi: 10.1007/s10570-018-1715-5

Montanari, S., Roumani, M., Heux, L., and Vignon, M. R. (2005). Topochemistry of carboxylated cellulose nanocrystals resulting from TEMPO-mediated oxidation. Macromolecules 38, 1665-1671. doi: 10.1021/ma048396c

Nishiyama, Y., Kim, U. J., Kim, D. Y., Katsumata, K. S., May, R. P., and Langan, P. (2003). Periodic disorder along ramie cellulose microfibrils. Biomacromolecules 4, 1013-1017. doi: 10.1021/bm025772x

Oguzlu, H., Danumah, C., and Boluk, Y. (2017). Colloidal behavior of aqueous cellulose nanocrystal suspensions. Curr. Opin. Coll. Interf. Sci. 29, 46-56. doi: 10.1016/j.cocis.2017.02.002

Ojala, J., Sirviö, J. A., and Liimatainen, H. (2016). Nanoparticle emulsifiers based on bifunctionalized cellulose nanocrystals as marine diesel oil-water emulsion stabilizers. Chem. Eng. J. 288, 312-320. doi: 10.1016/j.cej.2015. 10.113

Orts, W. J., Godbout, L., Marchessault, R. H., and Revol, J. F. (1998). Enhanced ordering of liquid crystalline suspensions of cellulose microfibrils: a small angle neutron scattering study. Macromolecules 31, 5717-5725. doi: 10.1021/ ma9711452

Pääkko, M., Ankerfors, M., Kosonen, H., Nykänen, A., Ahola, S., Österberg, M., et al. (2007). Enzymatic hydrolysis combined with mechanical shearing and high-pressure homogenization for nanoscale cellulose fibrils and strong gels. Biomacromolecules 8, 1934-1941. doi: 10.1021/bm061215p

Palaganas, N. B., Mangadlao, J. D., De Leon, A. C. C., Palaganas, J. O., Pangilinan, K. D., Lee, Y. J., et al. (2017). 3D printing of photocurable cellulose nanocrystal composite for fabrication of complex architectures via stereolithography.
ACS Appl. Mater. Interf. 9, 34314-34324. doi: 10.1021/acsami.7b 09223

Park, S., Baker, J. O., Himmel, M. E., Parilla, P. A., and Johnson, D. K. (2010). Cellulose crystallinity index: measurement techniques and their impact on interpreting cellulase performance. Biotechnol. Biofuels 3:10. doi: 10.1186/ 1754-6834-3-10

Qin, Y., Qiu, X., and Zhu, J. Y. (2016). Understanding longitudinal wood fiber ultra-structure for producing cellulose nanofibrils using disk milling with dilute acid prehydrolysis. Sci. Rep. 6:35602.

Revol, J.-F., Bradford, H., Giasson, J., Marchessault, R. H., and Gray, D. G. (1992). Helicoidal self-ordering of cellulose microfibrils in squeous suspension. Int. J. Biol. Macromol. 14, 170-172. doi: 10.1016/s0141-8130(05)80008-x

Schenzel, K., Fischer, S., and Brendler, E. (2005). New method for determining the degree of cellulose I crystallinity by means of FT Raman spectroscopy. Cellulose 12, 223-231. doi: 10.1007/s10570-004-3885-6

Segal, L., Creely, J. J., Martin, A. E., and Conrad, C. M. (1959). An empirical method for estimating the degree of crystallinity of native cellulose using the X-ray diffractometer. Text. Res. J. 29, 786-794. doi: 10.1177/0040517559029 01003

Shafiei-Sabet, S., Hamad, W. Y., and Hatzikiriakos, S. G. (2012). Rheology of nanocrystalline cellulose aqueous suspensions. Langmuir 28, 17124-17133. doi: $10.1021 / \mathrm{la} 303380 \mathrm{v}$

Shafiei-Sabet, S., Hamad, W. Y., and Hatzikiriakos, S. G. (2014). Ionic strength effects on the microstructure and shear rheology of cellulose nanocrystal suspensions. Cellulose 21, 3347-3359. doi: 10.1007/s10570-014-0407-z

Stojanović, Ž, Jeremić, K., Jovanović, S., and Lechner, M. D. (2005). A comparison of some methods for the determination of the degree of substitution of carboxymethyl starch. Starch 57, 79-83. doi: 10.1002/star.200400342

Šturcová, A., Davies, G. R., and Eichhorn, S. J. (2005). Elastic modulus and stress-transfer properties of tunicate cellulose whiskers. Biomacromolecules 6 , 1055-1061. doi: 10.1021/bm049291k

Sultan, S., and Mathew, A. P. (2018). 3D printed scaffolds with gradient porosity based on a cellulose nanocrystal hydrogel. Nanoscale 10, 4421-4431. doi: 10 . 1039/c7nr08966j

Wang, J., Chiappone, A., Roppolo, I., Shao, F., Fantino, E., Lorusso, M., et al. (2018). All-in-one cellulose nanocrystals for 3D printing of nanocomposite hydrogels. Angew. Chem. Intern. Edn. 57, 2353-2356. doi: 10.1002/anie. 201710951

Wang, Q. Q., Zhu, J. Y., and Considine, J. M. (2013). Strong and optically transparent films prepared using cellulosic solid residue (CSR) recovered from cellulose nanocrystals (CNC) production waste stream. ACS Appl. Mater. Interf. 5, 2527-2534. doi: 10.1021/am302967m

Wang, Q. Q., Zhu, J. Y., Gleisner, R., Kuster, T. A., Baxa, U., and McNeil, S. E. (2012a). Morphological development of cellulose fibrils of a bleached eucalyptus pulp by mechanical fibrillation. Cellulose 19, 1631-1643. doi: 10 . 1007/s10570-012-9745-x

Wang, Q. Q., Zhu, J. Y., Reiner, R. S., Verrill, S. P., Baxa, U., and McNeil, S. E. (2012b). Approaching zero cellulose loss in cellulose nanocrystal (CNC) production: recovery and characterization of cellulosic solid residues (CSR) and CNC. Cellulose 19, 2033-2047. doi: 10.1007/s10570-012-9765-6

Wang, R., Chen, L., Zhu, J. Y., and Yang, R. (2017). Tailored and integrated production of carboxylated cellulose nanocrystals (CNC) with nanofibrils (CNF) through maleic acid hydrolysis. Chemnanomat 3, 328-335. doi: 10.1002/ cnma. 201700015

Wang, W., Mozuch, M. D., Sabo, R. C., Kersten, P., Zhu, J. Y., and Jin, Y. (2015). Production of cellulose nanofibrils from bleached eucalyptus fibers by hyperthermostable endoglucanase treatment and subsequent microfluidization. Cellulose 22, 351-361. doi: 10.1007/s10570-014-0465-2

Wang, W., Mozuch, M. D., Sabo, R. C., Kersten, P., Zhu, J. Y., and Jin, Y. (2016). Endoglucanase post-milling treatment for producing cellulose nanofibers from bleached eucalyptus fibers by a supermasscolloider. Cellulose 23, 1859-1870. doi: 10.1007/s10570-016-0946-6

Yarbrough, J. M., Zhang, R., Mittal, A., Vander Wall, T., Bomble, Y. J., Decker, S. R., et al. (2017). Multifunctional cellulolytic enzymes outperform processive fungal cellulases for coproduction of nanocellulose and biofuels. ACS Nano 11, 3101-3109. doi: 10.1021/acsnano.7b00086

Zhou, H., St. John, F., and Zhu, J. Y. (2019). Xylanase pretreatment of wood fibers for producing cellulose nanofibrils: a comparison of different 
enzyme preparations. Cellulose 26, 543-555. doi: 10.1007/s10570-01902250-1

Zhu, J., Chen, L., Gleisner, R., and Zhu, J. Y. (2019). Co-production of bioethanol and furfural from poplar wood via low temperature $\left(\leq 90^{\circ} \mathrm{C}\right)$ acid hydrotropic fractionation (AHF). Fuel 254:115572. doi: 10.1016/j.fuel.2019. 05.155

Zhu, J. Y., Sabo, R., and Luo, X. (2011). Integrated production of nanofibrillated cellulose and cellulosic biofuel (ethanol) by enzymatic fractionation of wood fibers. Green Chem. 13, 1339-1344. doi: 10.1039/c1gc $15103 \mathrm{~g}$

Zhu, W., Houtman, C. J., Zhu, J. Y., Gleisner, R., and Chen, K. F. (2012). Quantitative predictions of bioconversion of aspen by dilute acid and SPORL pretreatments using a unified combined hydrolysis factor (CHF). Process Biochem. 47, 785-791. doi: 10.1016/j.procbio.2012.02.012
Conflict of Interest: Zhu and RG are co-inventors of the dicarboxylic acid hydrolysis process for producing CNMs.

The remaining authors declare that the research was conducted in the absence of any commercial or financial relationships that could be construed as a potential conflict of interest.

Copyright $\odot 2020$ Wang, Zhu, Ma, Agarwal, Gleisner, Reiner, Baez and Zhu. This is an open-access article distributed under the terms of the Creative Commons Attribution License (CC BY). The use, distribution or reproduction in other forums is permitted, provided the original author(s) and the copyright owner(s) are credited and that the original publication in this journal is cited, in accordance with accepted academic practice. No use, distribution or reproduction is permitted which does not comply with these terms. 